\author{
Garry D. Bruton \\ Louisiana State University \\ Baton Rouge, Louisiana \\ Roger Alexander \\ Management Consultant \\ Margaret A. White \\ Oklahoma State University \\ Stillwater, Oklahoma
}

Mergers and acquisitions (M\&As) are methods frequently used for corporate growth and diversification. In 1988 alone, over $\$ 226$ billion of mergers and acquisitions occurred in the United States [26]. While the volume of M\&As is impressive, their effect on performance is often less than what was expected. The merger of Dart Industries with Kraft Food, People's Express purchase of Frontier Airlines, and Mobile Corporation's purchase of Montgomery Ward \& Co. are just a few of the well publicized cases of M\&As which were unsuccessful in meeting financial goal expectations. In addition to these case studies there is strong evidence from empirical investigations which raises questions about their financial benefits. For example, Lubatkins's review of a number of merger and acquisition studies found that mergers do not benefit the acquiring firm with a return greater than it would receive from other investment opportunities with similar levels of risk [15]. Other researchers have found that "mergers have not increased profitability, have not improved efficiency, have not expanded sales and in fact, do not seem to yield sufficient benefit to anyoneconsumer and companies alike" [17].

A potential reason for the lack of M\&A success is the absence of adequate acquisition planning [2]. In particular, acquisition planners may not be considering process factors in their planning activities [13]. Adequate considerations of process factors would include the organizational and behavioral relationships which occur throughout a M\&A. To date, planners and researchers have largely ignored these relationships in their effort to improve M\&A performance.

This paper develops a model that integrates process factors into M\&A planning. The model builds on the previous research and prescriptive analyses of successful and unsuccessful approaches to $\mathrm{M} \& \mathrm{~A}$. In addition, this model of $\mathrm{M} \& \mathrm{~A}$ planning should be more effective than the previous models because it recognizes and integrates process factors from an acquisition planner's viewpoint. Acquisition planners are the people centrally involved in any of the stages of a M\&A.

The proposed model shown in Figure 1 recognizes that A\&M's have three stages: planning, acquiring, and integrating. 
Figure 1

Acquisition Planning Model

\begin{tabular}{|c|}
\hline \multicolumn{1}{c}{ Success } \\
\hline Integrating \\
\hline Acquiring \\
\hline Planning \\
\hline
\end{tabular}

\section{Planning Stage}

The planning stage of the model focuses on building strategic readiness for the acquisition. This stage of the model has three central elements: 1) generating top level commitment; 2) formulating the firm's objectives, and 3) preparing to move opportunistically. These three elements are shown in Figure 2.

Figure 2

Planning Stage

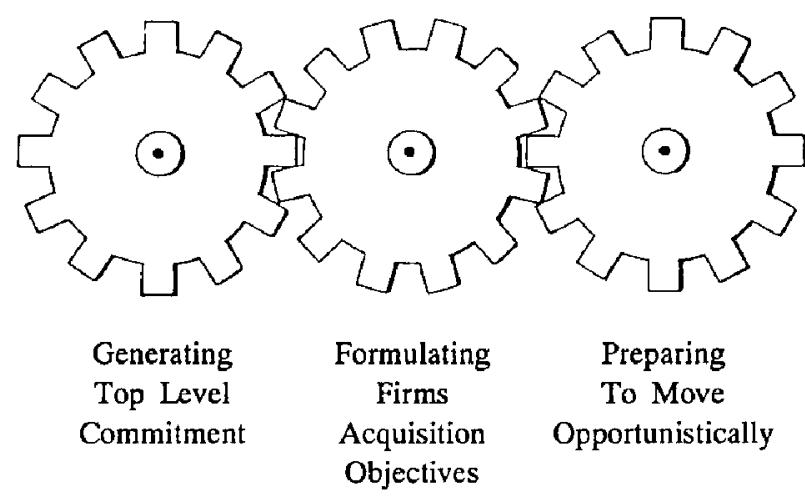

\section{Generating Top Level Commitment}

An acquiring company must develop a commitment among top level management to support the firm's acquisition program. Without the involvement of all top management personnel, implementation and involvement of lower level managers may be lacking. According to Drucker, these supporting actions during the M\&A are necessary for its success [9].

The harmful effect of the lack of commitment by top management was demonstrated in the Baker International Corporation and Hughes Tool Company merger which occurred in 1987. The extreme conflict of opinions of a former CEO and sitting Board members with the presiding CEO at the time of merger almost nullified the merger before it happened [10]. There were supporters for each man's viewpoint of the merger among the management of Baker. The resulting merger has provided fewer benefits than originally expected. Lack of agreement about the strategic worth of the merger created problems for the combined organization, Baker-Hughes, Inc. 


\section{Formulating the Firm's Acquisition Objectives}

Once top management has developed a commitment to an acquisition program, a set of objectives for that program should be developed by top level management and should fit the firm's strategy. Firms with successful acquisition programs formulate, as part of their objectives, a set of acquisition criteria to identify candidate firms [8].

The criteria must involve more than financial calculations. Instead, the use of acquisition criteria should ensure a strategic fit between the two firms. The need for this strategic fit is illustrated in the 1971 acquisition by General Host Corporation of Cudahy Company. General Host stated that "acquisition represents a significant step toward our goal of acquiring businesses with proven earnings." General Host divested Cudahy 10 years later stating "The divestiture of Cudahy will minimize our vulnerability to this cyclical commodity market" [1]. The focus by General Host Corporation strictly on financial concerns had blinded the corporation to whether a strategic fit would be present between the two firms.

The importance of such acquisition criteria to insure the strategic fit of the firms has been readily recognized by acquisition practitioners $[19,23,24$,$] . The acquisition criteria$ may be categorized as industry growth rate, degree of regulation, ease of entry, and capital versus labor intensity. Firm specific criteria may include quality of management in the acquired firm, size of market share, and capital structure.

While financial concerns should not dominate the objectives of the planner they must be considered. Financial criteria such as expected cash flow, asset value desired, and tax benefits expected from the acquisition should all be specified. The pursuit of synergy is one of the most common objectives of an M\&A. In fact, financial objectives of an M\&A are often based on the presence of possible synergy between the acquired and acquiring firms. The evidence concerning the presence of synergies in M\&As has been mixed. Chesebrough-Ponds bought Stauffer Chemical Company expecting synergy between the two firms' R\&D and marketing abilities. None was found; so when Unilever bought Chesebrough-Ponds in 1986 it soon began to divest the elements which has been part of Stauffer Chemical.

Empirical investigations found little evidence of synergistic effects. Haugen and Langetieg found no evidence of any synergy in the mergers they examined [11]. However, Chatterjee found that some financial synergies do exist in M\&As [5]. Financial synergies are derived from combining financial aspects of the two firms; the benefits of such synergies include obtaining lower cost of capital for the newly combined firm. However, little support was found for technical synergies which result from combining operations. The absence of synergy, particularly operating synergy, may be due to the difficulty in combining the personnel of two firms. Differences in operating procedures, culture, and employee competency introduce inefficiencies that eliminate any potential synergies. Therefore, the planner must be careful to insure that the financial objectives, which are based on potential synergies, are actually possible.

\section{Preparing to Move Opportunistically}

The final element in building the strategic readiness stage of the model is preparing to move opportunistically. Organizational and fiscal resources must be available for the 
M\&A. A common problem in acquisition is an underestimation of the requirements for the capital funds and management resources.

Such underestimation of resource requirements for an M\&A can be serious. Occidental Petroleum purchased Cities Service in 1982 . The $\$ 4$ billion purchase price combined with a lack of management depth and a downturn in the oil industry resulted in significant financial pressure being placed on Occidental. Occidental was forced to sell not only significant portions of the old Cities Service but also other assets to recover [25].

This third element is driven by the prior two elements. The financial and management resources and their sources must be consistent with the firm's acquisition objectives. Similarly, the ability to move opportunistically may be compromised without the support and commitment of top management. The speed and thoroughness required to be successful may not be possible if top management has not already committed to a plan of action.

In summary, the three elements of stage one of the model are driven by one another as seen in Figure 2. It is critical that the firm recognize the importance of these factors and insure they are in place to support the acquisition program.

\section{Acquiring Stage}

The acquiring stage of the model deals with the actual identification of the merger or acquisition candidate and the negotiations to purchase that firm. There are three key elements in this stage of the model (Figure 3). These are: 1) searching for acquisition candidates that meet acquisition criteria; 2) investigating organizational fit, and 3) negotiating the merger or acquisition.

Figure 3

Acquiring Stage

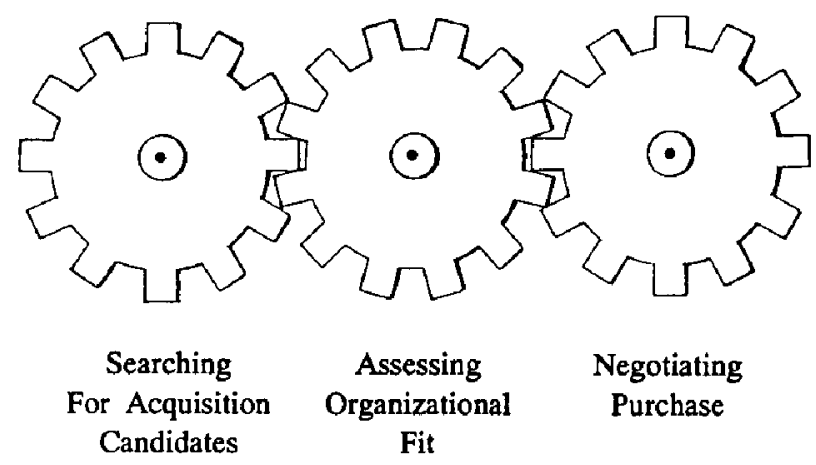

\section{Searching for Acquisition Candidate}

The initial task in Stage 2 of the acquisition planning process is to conduct a search for acceptable acquisition candidates. This is a proactive element of the M\&A process; the acceptable candidates are actively sought out. The basis of the analysis are the objectives and criteria that have been established in Stage 1 of the model. Industries are first screened to identify those that meet the acquisition criteria. Next, acquisition candi- 
dates are identified within the selected industries through an in-depth analysis of the industry participants. The acquisition candidates are those firms which most nearly match the acquisition criteria. Those firms that then match the criteria may be approached concerning a possible merger and acquisition. As Brian Saffer, First Vice President Bache Halsey Stuart Shield, stated "Everybody's for sale until proven otherwise" [20].

\section{Assessing Organizational Fit}

Once the acquisition candidate has been identified a more in-depth analysis is required to determine the degree of organizational fit. Organizational fit between the administrative, cultural and personnel characteristics of the two firms is critical to reduce potential postmerger problems [7]. The impact of these problems may range from being a "serious nuisance" for a large firm acquiring a small firm to "life threatening" for a small firm acquiring an equal size or larger firm. Therefore, prior to entering the negotiation process the acquiring firm should determine if a reasonable systematic fit can be expected [4].

One potential organizational fit issue is the difference in the administrative characteristics of two firms. For example, the differences in administrative characteristics between a small entrepreneurial firm and a larger more bureaucratic firm can be substantial. These differences impacted their potential success of Raythion's purchase of Lexitron Corporation in 1978. Lexitron had been a leader in word processing technology and Raytheon hoped to combine that knowledge with its computer terminal production to become a leader in the integrated office systems market. However, the marriage between the large established defence contractor and the high-tech entrepreneurial firm failed. By 1984 Raytheon sold its divisions of which Lexitron was a part, taking a $\$ 95$ million write-off. The bureaucratic administrative structure of Raytheon suffocated the entrepreneurial spirit of Lexitron [6].

Other large firms have had similar experiences with their purchase of entrepreneurial firms; Schlumberger's acquisition of Fairchild Camera and Instrument, and Exxon's purchase of Reliance Electric failed as the larger firm smothered the innovative climate of the smaller firm. The administrative difference between two firms does not necessarily have to lead to failure. Kraft's purchase of Celestial Seasonings involved similar bureaucratic and entrepreneurial firms [3]. However, Kraft was clearly aware of these administrative differences and sought to deal with them during and after the acquisition.

Culture is another critical part of organizational fit. Overall, culture can be defined as the assumptions, values, and perceptions of company practices in each firm. The culture of an organization shapes the behavior of the participants in that organization. The clash between two cultures can seriously inhibit postmerger performance as employees become unclear what values and actions are expected of them. For example, the acquisition of St. Joe Minerals Corporation in 1981 by its "white knight" Fluor Corporation resulted in such a clash of cultures.

Both organizations' management were highly respected. However, each firm had a distinct culture. St. Joe allowed managers considerable autonomy in their decision making and encouraged a structure more characteristic of a partnership than typical of a publicly traded corporation. Fluor, on-the-other-hand, had a very centralized structure with 
clear lines of democracy between various levels of the organization and a central corporate staff to make most critical decisions. The two cultures clashed and impeded the postmerger performance of the corporation. Managers must be aware of the culture and administrative structure of a proposed merger or acquisition and how those factors may impact organizational fit.

\section{Negotiation Process}

The majority of cancellations that occur in the negotiation phase are due to inadequate bids or the inability to obtain sufficient financing to meet the candidates's terms [16]. However, beyond these two difficulties there are additional issues that may cause a combination's failure; these issues center on through communication being provided to, and received from, the acquisition candidate. In 1980, Seagram's initially made an acquisition attempt for St. Joe Minerals. However, rather than contact the management of the firm directly, their announcement of intent to acquire was made through the press. As a result St. Joe began looking for a white knight, with Fluor purchasing the firm in 1981. St. Joe's president later said, "If Edgar Bronfman had talked to us first, it might have worked. We might have reached an agreement, maybe for $\$ 52$ a share" (Fluor paid $\$ 60$ a share) [12]. While Seagram's might not want to lose its strategic advantage by giving prior notice, some prior communication, or communication during the process, may have prevented losing the M\&A opportunity.

Finally, the negotiation process must communicate clearly what the acquiring firm is receiving for its purchase. the Ford Motor Company, in its 1987 acquisition of $75 \%$ of Aston Martin, thought it bought a $50 \%$ stake in the Italian design firm of Zagato. It had not, and Ford was left with a less attractive acquisition than it had originally envisioned. Therefore, it is critical that sufficient information be exchanged and clarified for a successful M\&A.

\section{Integrating Stage}

The planner's work is not finished once the acquisition occurs. The negotiation process to purchase a firm often results in an "agreement in principle." The resulting structure of the firm, personnel issues and other relevant items are left to be settled after the acquisition is completed. If the potential firm rejects the acquisition offer, a hostile takeover may follow. Issues of structure and personnel are again left unsettled. Therefore, whether the takeover is hostile or friendly substantial amounts of work remain for the planner. Too frequently, acquiring firms fail to plan how such issues will be addressed [8]. The third stage of the model examines integrating the acquired business with the acquiring company. This stage of the model has three elements (Figure 4): 1) establishing a transition team, 2) integrating the acquired firm, and 3) gaining equilibrium.

\section{Assigning the Executive Transition Team}

The first element of this stage is assigning the executive team to aid in the transition. When making acquisitions a firm should have a plan of action to assist in the transition 
[22]. The transition team should consist of key managers from each organization and should represent critical functions or major product lines in both firms. The transition team should develop a plan for integration of the firms and then help manage the integration of the two firms. The ultimate goal of the team should be to facilitate the integration of both individuals and operations of the previously independent entities.

Figure 4

Integrating Stage

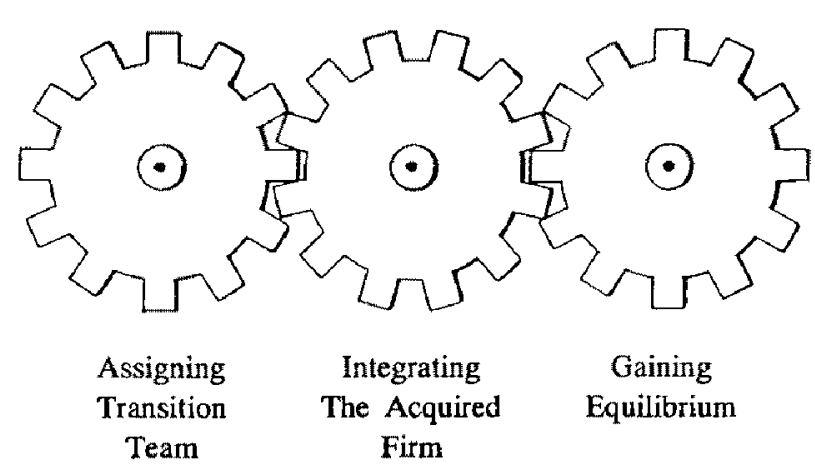

The transition team can also help to deal with the key concerns of the employees immediately following the announced M\&A. The transition of ownership is a highly stressful occurrence for employees [21]. Accurate communication, both up and down the acquired organization, is critical to limit such stress [16]. The transition team can help to provide this steady flow of information from the acquiring firm to the employees of the acquired firm to ease their anxieties. The acquisition planners should recognize the potential for stress and uncertainty among organizational constituents. They must deal quickly and effectively to eliminate potentially destructive actions, such as the loss of key personnel, customers, and supplies.

The successful Allied-Bendix merger illustrates the critical role a transition team can play in an M\&A. To facilitate the merger, a transition team was established representing senior managers from both Allied and Bendix. This team was drawn from the areas of finance, human resources, operations, law, tax, planning, public affairs, and technology. Sub-transition teams were then formed to deal with specific problems in each of these areas. The transition team had five months to arrive at total integration plan for the two firms. The transition teams and all senior managers sought to answer questions of employees as quickly as possible. Clear time lines were established as to when key information needed to be communicated to the employees. Major issues, such as key appointments as well as who was staying or leaving, were all answered in that first five months. The result was a highly successful combination of the two firms.

\section{Integrating the Acquired Firm}

Once an integration plan is established the acquiring firm should move quickly to structurally integrate the new firm into the company. Reporting relationships should be 
defined in a clear, precise manner. Kitching argued that "the setting up of unclear reporting relationships and the temptation to change them often; such action was present in 81 percent of (acquisition) failures" [14].

The actual integration, therefore, should be carried out in a timely manner with the resulting organizational structure having some stability for a period of time following the merger or acquisition.

The nature of the structure to be established after an M\&A must also be examined carefully. The easiest structure for the acquiring firm to formulate is to make the acquired firm a separate operating unit. However, the M\&A planner should establish organizational structure based on what is appropriate, not what is easy. Baxter International acquired American Hospital Supply Corporation in 1985. The organizational structure that resulted from this combination was substantially different than either firm's pre-M\&A structure. Baxter recognized that neither the control over personnel nor the potential economies of scale they desired could be provided by the structure either firm possessed. The new structure that was established allowed both of these issues to be addressed and helped provide Baxter a successful M\&A.

\section{Gaining Equilibrium}

After the firm's personnel and structures are integrated the focus of the planner is the return of the newly combined firm to a state of equilibrium. The planner's equilibrium is established by obtaining stability in the culture and key personnel attitudes of the acquired firm. They identified these attitude and the firm's culture in the analysis of organizational fit. However, the trauma of the M\&A and turnover in key personnel may cause a change in these items.

Planners need to continue to communicate to the employees about the M\&A and receive information about their feelings. Surveys or structured interviews are an excellent way to receive feedback from the employees. These feedback mechanisms will allow the firm's culture and key attitudes to be monitored. Particular problems that arise can then be identified and addressed.

DuPont's acquisition of Conoco and General Motors' acquisition of Hughes Aircraft are examples of firms which successfully sought to monitor and maintain key attitudes and culture in the firms they acquired. They did this by ensuring the retention of certain key individuals who reflected those values and making other specific efforts, such as through compensation, to reinforce certain values.

Acquiring firms should monitor their newly combined organization closely. If particular values appear to be diminishing, both symbolic and substantive actions should be taken to reenforce the desired values.

\section{Summary}

In summary, acquisition planners need to include process factors in their planning activities. The incremental model for incorporation of process factors into the M\&A planning process (with each element driving the other elements) should help managers adapt 
as new information becomes available [18].

Too often a $M \& A$ is viewed as a single event. By recognizing that a $M \& A$ is a process which begins before the consummation of the legal purchase and then continues after the purchase, the planner can develop a more thorough understanding of the M\&A. This understanding can help the planner smooth the transition between the two organizations and reach a new equilibrium state faster than might normally be experienced.

\section{Bibliography}

1. Achtmeyer, W.F. and Danniell, M.H. "How Advanced Planning Widens Acquisition Rewards." Mergers \& Acquisitios, Vol. 23 (July/August, 1988), pp. 37-42.

2. Ansoff, I. H., Avner, J., Brandenberg, R. G., Portner, F. E., and Radosevich, R. "Does Planning Pay? The Effect Of Planning On Success Of Acquisitions In American Firms." Long Range Planning, Vol. 3. No. 12 (1970) pp. 2-7.

3. Atchison, S. D. "Kraft Is Celestial Seasonings' Cup Of Tea." Business Week (July 28, 1986), p. 73.

4. Callahan, J. P. "Chemistry: How Mismatched Managements Can Kill A Deal." Mergers \& Acquisitions, Vol. 21 (March/April 1986), pp. 47-53.

5. Chatterjee, D. "Types Of Synergy And Economic Value: The Impact Of Acquisitions On Merging and Rival Firms.” Strategic Management Journal, Vol. 7 (1986), pp. 119-139.

6. Cohen, L. P. "Failed Marriages: Raytheon Is Among Companies Regretting High-Tech Mergers." Wall Street Journal (September, 1984), p. 1.

7. Davis, R.D. "Compatibility In Corporate Marriages." Harvard Business Review, Vol. 46 (1968), pp. 86-93.

8. DeNoble, A.F., Gustafson, L.T., and Hergert, M. "Planning For Post-Merger IntegrationEight Lessons For Merger Success." Long Range Planning, Vol. 21 (1988), pp. 82-85.

9. Drucker, P.F. "The Five Rules Of Successful Acquisition." The Wall Street Joumal (October 15, 1981).

10. Eklung, C.S. and Vogel, T. "Why The Baker-Hughes Merger Almost Didn't Happen." Business Week, (May 11, 1987), pp. 110-111.

11. Haugen, R.A. and Langetieg, T. C. “An Empirical Test For Synergism In Merger.” Journal of Finance, Vol. 30 (1975), pp. 1003-1014.

12. Hughes, K.A. "In Mergers, Manners Can Matter A Lot." Wall Street Journal (October 4, 1982), p. 35. 
13. Jemison, D.B. and Sitkin, S.B. "Corporate Acquisitions: A Process Prospective." Academy of Management Review Vol. 11 (1986).

14. Kitching, J. "Why Do Mergers Miscarry?" _Harvard Business Review, Vol. 45 Nol 6 (1967), pp. 84-101.

15. Lubatkin, M. "Mergers And Performance Of The Acquiring Firm." Academy of Management Review, Vol. 8 (1983), pp. 218-225.

16. McCann, J.E. and Gilkey, R. Joining Forces: Creating And Managing Successful Mergers And Acquisitions. Prentice-Hall: New Jersey (1988).

17. Pekar, P. "A Strategic Approach To Diversification." Joumal of Business Strategy, Vol. 5. No. 4 (1985) pp. 99-104.

18. Quinn, J.B. “Strategic Change: Logical Incrementalism." Sloan Management Review, Vol. 27 (1978), pp. 47-57.

19. Rockwell, Jr. W.F. "How To Acquire A Company." Harvard Business Review, Vol. 46, No. 5 (1968), pp. 121-132.

20. "Roundtable: Searching For The 'Right' Company." Mergers \& Acquisitions, Vol. 17 (Summer, 1982), pp. 23-30.

21. Shirley, R.C. “The Human Side Of Merger Planning." Long Range Planning, Vol. 10 (1977), pp. 35-39.

22. Sinetar, M. "Mergers, Morale And Productivity." Personnel Journal, Vol. 60 (1981), pp. $863-$ 867.

23. Temple, J.E. , Veal, Jr., T.G., and Smith, W.K. "Strategic Growth Through Merger And Acquisition." Financial Executive, Vol. 49, No. 5 (1981), pp. 13-16.

24. Terry, R.J. "Ten Suggestions For Acquisition Success." Managerial Planning, Vol 31, No. 5 (1982), pp. 13-16.

25. Wayne, L. "Executives Will Defend Its \$4 Billion Purchase Of Cities Service, Though Analysts Say Debts From The Deal Are Choking The Company." New York Times, (January 23, 1983).

26. “1988 Profile.” Mergers \& Acquisitions, Vol. 23, No. 6 (1989), p. 53. 